\title{
Research Paper: The Effectiveness of Narrative Therapy on Reducing the Fear of Intimacy in Couples
}

\author{
Seyedhadi Yeganehfarzand ${ }^{1}$ (i), Kianoush Zahrakar ${ }^{*}$ (1), Farshad Mohsenzadeh ${ }^{1}$ (i) \\ 1. Department of Counseling, Faculty of Psychology \& Education, Kharazmi University, Tehran, Iran.
}

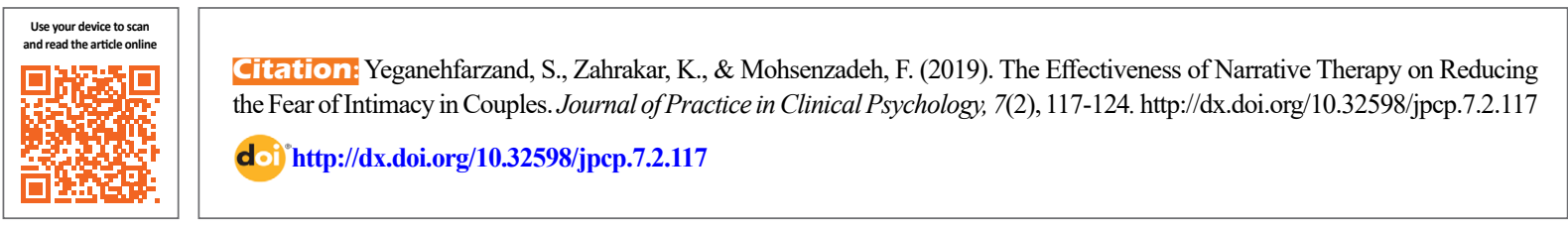

\section{(c) (1) (8)}

Article info:

Received: 26 Nov 2018

Accepted: 29 Feb 2019

Available Online: 01 Apr 2019

Keywords:

Narrative therapy, Fear, Couple therapy

\section{ABSTRACT}

Objective: This study aimed to investigate the effectiveness of narrative therapy on reducing the fear of intimacy in couples.

Methods: To achieve this purpose, the present research opted for a quasi-experimental study, including pre-test and post-test with a control group. The study population included couples seeking improvement in their relationships who attended Delphi Clinic, a center for counseling and psychological services in Tehran City, Iran. The study sample consisted of 12 couples (24 individuals) who had achieved the highest scores compared to the mean scores in the Fear of Intimacy Scale (FIS). Sampling was carried out through a purposive sampling method, and the members were randomly assigned to the experimental and control groups (each containing 6 couples). Having performed the pre-test and completed the FIS, the experimental group participated in the two-hour sessions of narrative therapy for 14 weeks, and the control group was put on the waiting list. At the end of the sessions, all 12 couples responded to the FIS again as the post-test.

Results: The data were analyzed using the analysis of covariance. According to the obtained results, $75 \%$ of the differences observed in the scores of the post-test FIS were caused by the effect of narrative therapy intervention. Therefore, with a $99 \%$ confidence, narrative therapy can reduce the fear of intimacy in couples when compared to the control group.

Conclusion: In summary, couple narrative therapy can reduce the fear of intimacy by constructing new meanings in couples' lives.

\section{* Corresponding Author:}

Kianoush Zahrakar, PhD.

Address: Department of Counseling, Faculty of Psychology \& Education, Kharazmi University, Tehran, Iran.

Tel: +98 (935) 8612985

E-mail:dr_zahrakar@yahoo.com 


\section{Highlights}

- By reducing the fear of intimacy, the relationship of couples will improve.

- Narrative therapy can significantly decrease fear of intimacy between couples.

- Narrative therapy is an effective method for improving couples' relationships.

\section{Plain Language Summary}

Family health largely depends on the health and happiness of the couple's relationship. According to the reported statistics, many marriages in Iran end in divorce. Most of these marriages were initially founded on the grounds of friendship. One of the factors that always affects the well-being and satisfaction of couples is intimacy. Since many studies show the importance of being intimate for improving couples' relationships, therapists have always been looking for ways to create more intimacy between couples. One of the most sought after practices is narrative therapy. In this approach, the therapist guides the couple to create a more effective narration through reviewing and reconstructing their dominant narrations. The results of this study indicate that narrative therapy is effective in the reduction of couples' fear of intimacy.

\section{Introduction}

arriage is a significant milestone for family and requires affection, commitment, emotional relationship, conflict resolution skill, and spirituality between the couple (Masters, 2008). Studies show that intimacy is an important and determining factor in marital satisfaction (Berman \& Lief, 1975; Schaefer \& Olson, 1981). Intimate relationships allow one to meet the need for acceptance, attention, value, and affection and express it to his or her partner (Fletcher, 2002). Intimacy is also an important factor in the creation of stable marriages (Crawford \& Unger, 1994) because it strengthens couples' commitment to the relationship and is positively associated with marital satisfaction and adaptability (Heller \& Wood, 1998).

It is, however, also possible to perceive intimacy as a scary situation, due to the damage suffered by people in their life background and the length of their relationship, which we call "fear of intimacy". For many people, under the influence of bitter childhood experiences and broken adult relationships, this fear is formed which in reality is some void intimacy, ultimately bringing up nothing but pain, suffering, and failure (Vangelisti \& Beck, 2007). The fear of intimacy in a relationship is a situation in which a person resists sharing his/her thoughts and feelings with his/her spouse and feels uncomfortable. In this situation, the individual's ability to express intimacy is diminished, and the person's desire to establish and maintain communication and express emotions are dashed (Descutner \& Thelen, 1999). This situation escalates to the extent that the couple gets tired of one another, alienated, and as such, they turn to a therapist stating that they cannot keep going and that their marital inadaptability is their partner's fault. These conditions not only reduce their marital satisfaction but also pose a high risk of separation and divorce (Gottman \& Levenson, 2000). Consequently, many therapeutic strategies have been employed to improve marital life, among which is the narrative therapy.

The couple narrative therapy was introduced by White and Epston (1990). It has a postmodern approach to the issues related to couples. In this outlook, marital conflicts are caused by narratives full of problems that change cognitive processes and coping strategies by shaping the identities of couples (Freedman \& Combs, 1996). These narratives do not allow the person to think about horizons, results, and events that include his/her merits, and enslave him/her in dominant stories that overwhelm all other narratives (Abedi, 2006). Therefore, the therapeutic narrative seeks to expand the experiences and possibilities of the couple with helping them to reconstruct and retell the new stories.

This approach is the process of assisting a person encounter one's issues through engagement in therapeutic conversations and entails retelling and rehearing. In this view, it is believed that people are not their problems and that issues exist outside them. People are specialists when it comes to their problems, and they have many 
skills, beliefs, values, and abilities that help them reduce the effects of these problems and provide them with a way to find meaning in their lives (Priscilla \& Vandergriff-Avery, 2001). Nowadays, therapists use narrative therapy to examine the assumptions about the dynamics of close and intimate relationships between couples (Skerrett, 2010). Studies have shown that the stories the couples have about their relationship reflect their efforts to form the narrative meaning of their experiences of intimacy with another couple (Frost, 2013) and telling the couple's life story can be of assistance to the therapist to improve the marital relationship (Skerrett, 2010). According to this point of view, problems are seen as stories that people have agreed to tell themselves (Blanton \& Vandergriff-Avery, 2001).

Narrative couple therapy is an attempt to facilitate the process of collaborative rewriting in couples' problematic narratives which shape their relationship. The treatment process is to examine how people analyze the story of their lives, with the central emphasis on creating new positive meanings in life (Goldenberg \& Goldenberg, 2015). When narratives are used as a way of better understanding the couple's intimacy, they increase individual potentials for the development of intimate relationships. That is because understanding the other side's story increases investment opportunities in the person's intimate relationship with one's partner (Skerrett, 2010; Banker, Kaestle, \& Allen, 2010). In previous studies, little attention has been paid to the effectiveness of post-modern therapies in the sense of newer therapeutic approaches.

Consequently, given the importance of the concept of intimacy, short-term therapies are needed to help couples in the field of intimacy. Because of the rising divorce rate in Iran which is mainly affected by behavioral problems and couple's inability in creating a mutually understanding relationship, gaining access to and acknowledging novel methods which aid therapists in reducing couples' conflicts seem necessary. And as no research has been conducted in Iran on applying narrative therapy to lessen the fear of intimacy, in this research, the researchers questioned whether the application of narrative therapy approach could reduce the fear of intimacy between couples.

\section{Methods}

To carry out this research, a quasi-experimental study with pre-test and post-test design with a control group was used. Data collection started a few months before the research being carried out. The potential participants were notified through flyers and brochures handed out to them at Delphi Clinic, a center for counseling and psychological services in Tehran City, Iran. The qualified couples who had been volunteered for the research were briefed about the therapy sessions they were about to receive. After the briefing session, if they still consented to take part in the study, they were asked to fill in the FIS questionnaire, both as a pre-test and as a screening tool from which the study participants would be selected.

Based on the obtained mean score, 12 couples (24 individuals) who met the study inclusion criteria were chosen and randomly assigned to experimental and control groups, each containing 6 couples (12 individuals). The inclusion criteria for entering the program were as follows: Having high school diploma, completing the moral principles form, participating in all therapy sessions, having been legally married to one another for at

Table 1. Summary of activities performed during the therapeutic session

\begin{tabular}{|c|c|}
\hline Therapeutic Session & Activities Performed \\
\hline First & Orientation and being informed about group rules and activities \\
\hline Second and third & Investigating problematic narrations of group members \\
\hline Fourth and fifth & Externalizing problems and accepting them as an external enemy to strengthen couples' alliance \\
\hline Sixth and seventh & Challenging and deconstructing narrations \\
\hline Eighth and ninth & Discovering new meanings as well as alternative, preferred narrations \\
\hline Tenth and eleventh & Rewriting their life stories as couples \\
\hline Twelfth and thirteenth & A return to the problematic events \\
\hline Fourteenth & Reviewing topics once more and enriching couples' alternative stories \\
\hline
\end{tabular}


least one year, not considering divorce at the time, and not receiving any other psychological services or individual counseling. The exclusion criteria were having a record of hospitalization in psychiatric hospitals, using psychoactive drugs, and using illegal drugs and alcohol. Furthermore, to respect the research ethics, the participants were informed of the purpose of the research, the right to withdraw from the study at any time and the nondangerous nature of the intervention and their consent was obtained for taking part in the research.

To implement the research plan, a narrative therapy intervention was conducted in the form of 14 two-hour sessions on the members of the experimental group. Table 1, there is a summary of the routine during therapeutic sessions. Descriptive statistics such as mean and standard deviation and inferential statistics such as Analysis of Covariance (ANCOVA) were used to analyze the collected data. Before using the parametric test of covariance analysis, Levene's test was used to verify assumptions of homogeneity of variance. It should be noted that all statistical operations were performed in SPSS.

The Fear of Intimacy Scale (FIS) was used to collect the study data. This scale was constructed by Descutner and Thelen (1991) to assess the inhibition and capacity level of people to exchange thoughts and feelings in close and romantic relationships, and has 35 items scored in a 5-point Likert-type scale (grade 1 is “I'm not like this at all", and grade 5 is "This describes me perfectly"). A high score reflects a greater fear of intimacy. Descutner and Thelen's (1991) preliminary study showed that this scale has high internal consistency and test-retest reliability of 0.93 and 0.89 , respectively. Validity and reliability of this scale have been confirmed on the Iranian population. In the research of Fallahzadeh, Sanaei Zaker, and Farzad (2012) on a sample of 567 married male and female participants in Tehran, the estimated reliability through internal consistency was 0.83 , and the test-retest result was reported as 0.92 . The correlation of this scale with Walker \& Thompson's Intimacy scale (1983) has been reported as -0.58 , which indicates its divergent validity (Walker and Thompson, 1983).

\section{Results}

The demographic investigation of the study group showed that half of the participants were female, and half were male. Most of them had a bachelor's degree. The mean age of participants was 27.6 years, and their age ranged from 22 to 37 years. Table 2 shows the pretest and post-test raw scores of the experimental and control group. As the pre-test, post-test design was used to compare the effect of the intervention, the pre-test sensitization could have been a possibility. Thus, the Analysis of Covariance (ANCOVA) method was used to control it. However, before using this parametric test, two tests were used to verify its assumptions. The Shapiro-

Table 2. Pre-test and post-test raw scores of the experimental and control group

\begin{tabular}{cccccc}
\hline \multirow{2}{*}{ Variable } & Statistic & \multicolumn{2}{c}{ Narrative Therapy (Experimental) } & \multicolumn{2}{c}{ Control } \\
\cline { 3 - 5 } & & Pre-Test & Post-Test & Pre-Test & Post-Test \\
\hline $\begin{array}{c}\text { Fear of intimacy } \\
\text { scale score }\end{array}$ & M & 106 & 59.91 & 87.08 & 84.75 \\
& SD & 34.48 & 13.58 & 24.93 & 24.85 \\
\hline
\end{tabular}

Table 3. The Shapiro-Wilk test results to check the assumption of normality in the scores of the dependent variable

\begin{tabular}{ccccc}
\hline \multirow{2}{*}{ Fear of Intimacy } & Group & \multicolumn{3}{c}{ Shapiro-Wilk } \\
\cline { 3 - 5 } & & Statistic & df & Sig. \\
\hline \multirow{2}{*}{ Pre-test } & Experimental & 0.947 & 12 & 0.851 \\
& Control & 0.859 & 12 & 0.602 \\
Post-test & Experimental & 0.947 & 12 & 0.589 \\
& Control & 0.885 & 12 & 0.162 \\
\hline
\end{tabular}


Table 4. Levene's test to check the homogeneity assumption of the variance of the dependent variables

\begin{tabular}{ccccc}
\hline Test & $\mathbf{F}$ & $\mathbf{d f}_{1}$ & $\mathbf{d f}_{2}$ & $\mathbf{P}$ \\
\hline Pre-test & 1.978 & 1 & 22 & 0.174 \\
Post-test & 0.451 & 1 & 22 & 0.509 \\
\hline & & & & PRACICE in PSCAL PSY \\
\hline
\end{tabular}

Table 5. Results of one-variable variance analysis for comparing the total post-test score

\begin{tabular}{ccccccc}
\hline Source & Sum of Squares & df & $\begin{array}{c}\text { Mean Sum of } \\
\text { Squares }\end{array}$ & F & P & $\boldsymbol{\pi}$ \\
\hline Pre-test & 6607.9 & 1 & 6607.9 & 62.58 & 0.000 & 0.74 \\
Control group & 6913.86 & 1 & 6913.86 & 65.48 & 0.000 & 0.75 \\
Error & 2217.26 & 21 & 105.58 & & & \\
Total & 138096 & 24 & & & PRACTICE EL PSYCH L LOGY \\
\hline
\end{tabular}

Wilk test was used to check the normality in frequentist statistics as well as the Box's M and Levene's tests to check the homogeneity of covariance matrices. As Table 3 shows, the significance level in the Shapiro-Wilk test is higher than 0.05 , so the assumption of the normality of data in the pre-test stage is established. Furthermore, the significance level of the Shapiro-Wilk test indicates the normal distribution of data in the post-test phase. To test the hypothesis that narrative therapy reduces couples' fear of intimacy, the narrative therapy group and the control group are compared. To do this, the statistical method of one-factor analysis of covariance was used, which its results are presented later.

As shown in Table 4, the level of significance in the Levene's test is greater than 0.05 , so the variance of the groups is consistent and homogeneous. As it can be seen in the Table 5, the covariate variable (pre-test) is significantly related to the dependent variable, but after eliminating the effect of the pre-test variable between the experimental group and the control group, a significant difference can be seen in FIS scores. The calculated F value of 65.48 with 21 and 1 degrees of freedom is greater than the critical value of 8.34 , and in addition to that, the effect or difference is equal to 0.75 . In other words, $75 \%$ of the observed differences in the post-test scores of fear of intimacy is explained by the effect of narrative therapy intervention. Therefore, with $99 \%$ confidence, it can be said that narrative therapy can decrease fear of intimacy in comparison to the control group.

\section{Discussion}

The purpose of this study was to investigate the effectiveness of narrative therapy on reducing the fear of intimacy among couples, and the results suggest that this intervention has significantly reduced the couples' fear of intimacy. Our results are consistent with previous research findings such as those done by Frost (2011; 2013), Sanderson and Karetsky (2002), and Bartholomew (1990). Frost (2013) studied 150 people with long-term marital relationships, on how the narrative of intimacy was constructed and how the impact of relationship narratives predict the stability, relationship quality, and mental health. His results indicate that narratives with the content of intimate relationships are positively related to the quality of marital relationships and mental health.

Frost acknowledged that the strongest predictor for relationship quality and mental health was the narratively constructed affective tone of relationship story endings. That is to say, the narrative construction of positive story endings significantly increases the likelihood of participating couples remaining together over time. Also, Khodabakhsh, Kiani, Nouri Tiratashi, and Khastouheshjin (2014) also acknowledged the effectiveness of narrative therapy on various dimensions of couples' intimacy and stated that this method increased the couples' empathy and mindfulness, and it also facilitated the expressing of their feelings. Thus, this method could be 
beneficial in creating a space for rewriting difficult narratives.

Although in Iran, no research has been conducted that directly investigates the effect of narrative therapy on reducing fear of intimacy, other studies such as Rabiee, Fatehizadeh, and Bahrami (2008), Mirzadeh and Fallahchay (2012), Ahmadi, Borghei, and Abbassi (2016), Behradfar, Jazayeri, Bahrami, Abedi, Etemadi, and Fatemi (2016), Vacy (2012), Nouri Tir-tashi and Kazemi (2012), Narimani, Abbasi, Bagyan, and Bakhti (2014), Naeimi and Shirashtiani (2016) studied the effectiveness of narrative therapy on various effective variables which are influential in couple's relationships. These effective variables are modifying maladaptive schemas, controlling emotions, tendency to forgive, marital quality, family functioning, and reducing marital conflicts. The results of these studies often support the usefulness of this therapeutic approach. The reason for this benefit can be explained by glancing at the basics of narrative therapy.

Perhaps the main purpose of couple's narrative therapy is to create the opportunity to examine, critique, deconstruct, and rewrite couple narratives. In this view, the emphasis is on the fact that the person is not the problem, the problem is the problem. But when couples repeat their obligatory and difficult narratives through dialogues over and over, they stabilize them and assume that this is the whole truth. In reality, however, they ignore many exceptions in the shadow of these main lines and by being encircled by the narrative they have made, they find themselves in a situation that makes them assume the other partner is the problem. Meanwhile, by creating a space for reviewing couples' narratives, examining exceptions, and externalizing the problems, narrative therapy can free the couple from the domination of prevailing stories, and opens up hopes and new horizons for them. This is the atmosphere in which the couple finds a better understanding of each other by hearing another one's narration.

In this approach, the therapist, with the help of the clients, and by thickening and enriching their narratives, evokes flexibility and pragmatism in them, which leads to new possibilities in their life (Rostami Sani, 2007). The situation is similar to what White and Epston (1990) stated that by constructing new meanings, unpleasant feelings in couples alter. In the eyes of the external viewers, the question and answer between the therapist and the couple is perhaps the most evident occurrence in the treatment process. A question and answer that leads to the formation of more questions and broader responses and accompanies the individual in isolating oneself from the problem. This process of expanding and changing the couple's narrations of themselves and their influence on their stories is what changes their emotions toward each other (Ghaderi, Khodadadi, and Abbasi, 2010).

The narrative therapy by helping spouses to express their narratives allows them to break down the dominant narratives of their problem from the construction of the relationship and to forget the spatial or marginalized spaces of their communication narratives. Furthermore, by externalizing problems, couples find out that neither they nor their partners are the source of problems and that they can approach each other better than before in an atmosphere of interaction and this leads to an increase in couples' empathy, mindfulness, and emotion expression. And perhaps most importantly, it creates a space for making alternative narrations which can replace problematic stories (Payne, 2016; Madigan, 2017).

According to the principles of narrative therapy, people organize their experiences through their narratives. Narrations that are sometimes so full of problematic stories that do not leave any room for individual initiative. These narratives can also excite different emotions in one person, so people can summon new emotions in themselves by changing their narratives. In the course of this therapy, members are asked to narrate their stories innovatively, through taking into account their experiences, results, and unique possibilities.

They are also invited to create novel opportunities by reading between the lines and considering marginal capacities of their narratives. This reconstruction, however, is solely achieved through the persistent inquiries of the narrative therapist, the separation of the individual from the problem, and the enrichment of the story. With this effort, one achieves a new and more effective narrative about oneself, one's spouse, and one's relationship, which leads to a sense of trust in empowerment, a reduction in the fear of relationships, and thus a greater intimacy in one's narrative discourse. In summary, the couple narrative therapy can reduce the fear of intimacy by constructing new meanings in couples' lives.

\section{Ethical Considerations}

\section{Compliance with ethical guidelines}

The present research is a part of the first author's $\mathrm{PhD}$ dissertation of Department of Counseling, Faculty of Psychology \& Education, Kharazmi University. All participants in this study signed a consent letter. Furthermore, upon completion of the study, fourteen other ses- 
sions were held to provide therapeutic services for the control group.

\section{Funding}

The present research was personally funded by Seyedhadi Yeganehfarzand.

\section{Authors' contributions}

Conceptualization: Seyedhadi Yeganehfarzand, Kianoush Zahrakar; Methodology: Seyedhadi Yeganehfarzand, Farshad Mohsenzadeh; Software, Validation, Formal analysis, Investigation, Data curation, Writing, original draft, Resources: Seyedhadi Yeganehfarzand; Writing, review and editing: All authors; Supervision: Kianoush Zahrakar, Farshad Mohsenzadeh.

\section{Conflict of interest}

The authors declared no conflict of interest.

\section{Acknowledgments}

We would like to express our deepest gratitude to Delphi Clinic Staff for their support and help.

\section{References}

Abedi, A. (2006). [Storytelling in a narrative style (Persian)]. Paper presented at: Paper presented at The First National Congress of Art Therapy in Iran. 28-30 November; Tehran, Iran.

Ahmadi, S., Borghei, S., \& Abbassi, Z. (2016). [Comparison between the effect of education on the basis of attachment narrative therapy and apirituality on marital conflicts (Persian)] Islam and Psychological Research Journal Quarterly, 2(4), 99-112.

Banker, J. E., Kaestle, C. E., \& Allen, K. R. (2010). Dating is hard work: A narrative approach to understanding sexual and romantic relationships in young adulthood. Contemporary Family Therapy, 32(2), 173-91. [DOI:10.1007/s10591-009-9111-9]

Bartholomew, K. (1990). Avoidance of intimacy: An attachment perspective. Journal of Social and Personal Relationships, 7(2), 147-78. [DOI:10.1177/0265407590072001]

Behradfar, R., Jazayeri, R., Bahrami, F., Abedi, M., R., Etemadi, O., \& Fatemi, S. M. (2016). [A comparative scrutiny of the effectiveness of Emotionally-Focused Couple Therapy (EFCT) and Narrative Couple Therapy (NCT) in the marital quality and emotional, cognitive and behavioral impaired functioning of distressed couples (Persian)]. Family Psychology, 3(1), 3-16.

Berman, E. M., \& Lief, H. L. (1975). Marital therapy from a psychiatric perspective: An overview. American Journal of Psychiatry, 132(6), 583-92. [DOI:10.1176/ajp.132.6.583] [PMID]
Blanton, P. W., \& Vandergriff-Avery, M. (2001). Marital therapy and marital power: Constructing narratives of sharing relational and positional power. Contemporary Family Therapy 23(3), 295-308. [DOI:10.1023/A:1011131032386]

Crawford, M., \& Unger, R. (1994). Gender issues in psychology. Companion Encyclopedia of Psychology, 2, 1007-27.

Descutner, C. J., \& Thelen, M. H. (1991). Development and validation of a fear of intimacy scale. Psychological Assessment 3(2), 218-25. [DOI:10.1037/1040-3590.3.2.218]

Falahzade, H., Sanai Zaker, B. \& Farzad, V. (2013). [A study on the effectiveness of emotionally focused couple therapy and integrated systemic couple therapy on reducing intimacy anxiety (Persian)]. Family Research, 8(4), 465-84.

Fletcher, G. (2002). The new science of intimate relationships. Hoboken: Wiley-Blackwell. [DOI:10.1002/9780470773390]

Freedman, J., \& Combs, G. (1996). Narrative therapy the social construction of preferred realities. New York: WW Norton \& Company.

Frost DM. (2011). Stigma and intimacy in same-sex relationships: A narrative approach. Journal of Family Psychology, 25(1):1-10. [DOI:10.1037/a0022374] [PMID]

Frost, D. M. (2013). The narrative construction of intimacy and affect in relationship stories Implications for relationship quality, stability, and mental health. Journal of Social and Personal Relationships, 30(3), 247-269. [DOI:10.1177/0265407512454463]

Ghaderi, Z., Khodadadi, Z., \& Abbasi, Z. (2010). [On the effectiveness of the integrated approach with redecision and narrative therapies in controlling adolescent girls' emotions (Persian)]. Journal of Women and Society, 1(3), 137-48.

Goldenberg, H. \& Goldenberg, I. (2015). Family therapy. ( $8^{\text {th }}$ edition) [M. Firouzbakht, Persian Trans.]. Tehran: Rasa.

Gottman, J. M., \& Levenson, R. W. (2000). The timing of divorce: Predicting when a couple will divorce over a 14 years period. Journal of Marriage and the Family, 62(3), 737-45. [DOI:10.1111/ j.1741-3737.2000.00737.x

Heller, P. E., \& Wood, B. (1998). The process of intimacy: Similarity, understanding and gender. Journal of Marital and Family therapy, 24(3), 273-88. [DOI:10.1111/j.1752-0606.1998. tb01085.x] [PMID]

Khodabakhsh M, Kiani F, Nouri Tiratashi I, \& Khastouheshijn H. (2014). [The effectiveness of narrative therapy on increasing couples intimacy and its dimensions: Implication for treatment (Persian)]. Semi-annual Journal of Family Counseling and Psychotherapy, 4(4), 607-31.

Madigan, S. (2017). Narrative therapy: Theory and practice [A. H. Khajeh, \& A. A. Amiri, Persian Trans.]. Tehran: Daanzheh.

Masters, A. (2008). Marriage, commitment and divorce in a matching model with differential aging. Review of Economic Dynamics, 11(3), 614-28. [DOI:10.1016/j.red.2007.08.005]

Mirzadeh, M., \& Fallahchay, R. (2012). The relationship between forgiveness and marital satisfaction. Journal of Life Sciences and Biomedicine, 2(6), 278-82.

Naeimi, E., \& Shirashtiani, A. (2016) [Effectiveness of the combination of solution-focused therapy and narrative therapy on vitality and emotional control in divorce applicant women 
(Persian)]. Journal of Counseling Culture and Psychotherapy, 7(27), 149-69.

Narimani, M., Abbasi, M., Bagyan, M. J. \& Bakhti, M. (2014). [Comparison of two approaches based on Acceptance and Commitment Training (ACT) and a modified version of group therapy on early maladaptive schemas in clients in divorce (Persian)]. Journal of Family Counseling and Psychotherapy, 4(1), 1-28.

Nouri Tirtashi, E. \& Kazemi, N. (2012). [The effectiveness of narrative therapy on amount of forgiveness in women (Persian)]. Journal of Clinical Psychology, 4(2), 71-8.

Payne, M. (2016). Narrative therapy: An introduction for counselors [M. Esmailie Nasab \& H. Panahi, Persian Trans.]. Tehran: Roshd.

Priscilla, W. B., \& Vandergriff-Avery, M. (2001). Marital therapy and marital power: Constructing narratives of sharing relational and positional power. Contemporary Family Therapy, 23(3), 259-308. [DOI:10.1023/A:1011131032386]

Rabiee, S., Fatehizadeh, M., \& Bahrami, F. (2008). [The effect of narrative couple therapy on couples' family functioning in Isfahan (Persian)]. Family Research, 4(14), 179-91.

Rostami Sani, L. (2007). [Effectiveness of narrative therapy in reducing depression in female dormitory students (Persian)] [MSc. thesis]. Tehran: Allameh Tabatabaei University.

Sanderson, C. A., \& Karetsky, K. H. (2002). Intimacy goals and strategies of conflict resolution in dating relationships: A mediational analysis. Journal of Social and Personal Relationships, 19(3), 323-43. [DOI:10.1177/0265407502193002]

Schaefer, M. T., \& Olson, D. H. (1981). Assessing intimacy: The PAIR inventory. Journal of Marital and Family Therapy, 7(1), 4760. [DOI:10.1111/j.1752-0606.1981.tb01351.x]

Skerrett, K. (2010). Good enough stories: Helping couples invest in one another's growth. Family Process, 49(4), 503-16. [DOI:10.1111/j.1545-5300.2010.01336.x] [PMID]

Vacy, A. (2012). [Designing and comparing of two therapy programs based on narrative therapy principles and therapy based on Quran teachings in reduction of marital conflicts (Persian)]. Semi-Annual Journal of Family Counseling and Psychotherapy, 2(3), 340-57.

Vangelisti, A. L., \& Beck, G. (2007). Intimacy and fear of intimacy. In L. L. Abate, D. D. Embry, \& M. S. Baggett (Eds.) Low-Cost Approaches to Promote Physical and Mental Health (pp. 395-414). Berlin: Springer. [DOI:10.1007/0-387-36899-X_20]

Walker, A. J. \& Thompson, L. (1983). Intimacy and intergenerational aid and contact among mothers and daughters. Journal of Marriage and Family, 45(4), 841-9. [DOI: 10.2307/351796] [DOI:10.2307/351796]

White, M., \& Epston, D. (1990). Narrative means to therapeutic ends. New York: WW Norton \& Company. 